\title{
Research on Photocatalytic Degradation of Methyl Orange by a $\beta$-Cyclodextrin/Titanium Dioxide Composite
}

\author{
Shuting Lu, Nan Sun, and Ting Wang* \\ College of Science, Northeast Forestry University, Harbin, Heilongjiang 150040, China
}

\begin{abstract}
A photocatalytic composite of $\beta$-cyclodextrin/titanium dioxide $\left(\beta-\mathrm{CD} / \mathrm{TiO}_{2}\right)$ was synthesized via the photoinduced assembly method in this work. The morphology of the composite was characterized by scanning electron microscope (SEM) and transmission electron microscopy (TEM), respectively. The chemical composition was detected by fourier transform infrared spectroscopy (FTIR). By means of phenolphthalein probe technique and back titration method, the contents of active $\beta$ - $\mathrm{CD}(2.0 \%)$ and $\mathrm{TiO}_{2}(0.0971 \pm 0.0006 \mathrm{~g} / 0.1 \mathrm{~g})$ in the prepared $\beta$ - $\mathrm{CD} / \mathrm{TiO}_{2}$ composite were obtained. In order to investigate deeply the role of $\beta$ - $\mathrm{CD}$ in $\mathrm{TiO}_{2}$ photocatalytic system, $100 \mathrm{~mL}$ of $0.1 \mathrm{mmol} \mathrm{L}^{-1}$ methyl orange (MO) aqueous solution was used as the organic pollutant, the photocatalytic activity of $\beta-\mathrm{CD} / \mathrm{TiO}_{2}$ and pure $\mathrm{TiO}_{2}$ were assessed under the same conditions. The results showed that the degradation time of $\beta-\mathrm{CD} / \mathrm{TiO}_{2}$ was $43 \%$ shorter than that degraded by the aqueous solution containing only $\mathrm{TiO}_{2}, \beta-\mathrm{CD} / \mathrm{TiO}_{2}$ demonstrated a better photocatalytic activity. The kinetics of photocatalytic degradation of $\mathrm{MO}$ by $\beta-\mathrm{CD} / \mathrm{TiO}_{2}$ and pure $\mathrm{TiO}_{2}$ was studied. In addition, the degradation efficiency of $\mathrm{MO}$ by $\beta$-CD/ $/ \mathrm{TiO}_{2}$ was still above $85 \%$ after recycling for 5 times.
\end{abstract}

Keywords $\beta$-cyclodextrin, titanium dioxide, methyl orange, mechanism, photocatalytic degradation

\section{Introduction}

In recent years, the use of $\mathrm{TiO}_{2}$ as photocatalytic semiconductor material is extensively and intensively studied for its non-toxic nature, photochemical stability and strong oxidizing power under ultraviolet light. ${ }^{[1,2]}$ The applications of $\mathrm{TiO}_{2}$ and its modification to photocatalytic degradation of dyes, ${ }^{[3-6]}$ various organic pollutants, ${ }^{[7-9]}$ and reduction of heavy metals ${ }^{[10-13]}$ have been reported by many researchers. However, the high electron-hole recombination rate makes $\mathrm{TiO}_{2}$ become a relatively inefficient photocatalyst. ${ }^{[14]}$

Cyclodextrins (CDs) are produced as a result of intramolecular transglycosylation reaction from degradation of starch by cyclodextrin glucanotransferase enzyme ${ }^{[15]}$ The $\mathrm{CD}$ molecules are non-reducing cyclic oligosaccharides consisting of six to eight glucopyranose units linked by $\alpha-(1,4)$ bonds. ${ }^{[16]}$ The structure of CDs is similar a truncated cone with a hydrophobic inner cavity and a hydrophilic outer surface allowing to interact with a wide range of molecules and forming inclusion complexes through host-guest interactions. ${ }^{[17-19]}$ Recently, $\beta$-CD was added to the photocatalytic degradation systems in order to improve the photocatalytic degradation efficiency of $\mathrm{TiO}_{2} \cdot{ }^{[20-22]}$ It plays electron-donating and hole-capturing roles when linked to $\mathrm{TiO}_{2}$, which restricts charge-hole recombination and makes further improvement of photocatalytic degradation efficiency. ${ }^{[23]}$ Furthermore, based on the hydrophobic inner cavity of $\beta$-CD, the charge transfer rate from the photoexcited semiconductor to electron acceptors is accelerated and the photocatalytic substrates are concentrated onto the $\mathrm{TiO}_{2}$ surface. ${ }^{[2]}$ However, few reports focus on photodegradation kinetics models for explaining the role of $\beta$-cyclodextrin in the photocatalytic degradation.

In this work, we proposed that $\beta$-CD can form inclusion complexes with the hydrophobic part of methyl orange (MO), and the negatively charged part was more easily to be adsorbed on the sur- face of $\mathrm{TiO}_{2}$ for photocatalytic degradation. Meanwhile, three kinetics models were used to investigate the photocatalytic degradation process.

\section{Experimental}

\section{Reagents}

$\beta$-CD was purchased from TCI (Japan). $\mathrm{TiO}_{2}$ (anatase, particle size $<25 \mathrm{~nm}, 99.8 \%$ metal basis), MO and ammonium hydroxide $\left(\mathrm{NH}_{3} \cdot \mathrm{H}_{2} \mathrm{O}\right)$ were obtained from Shanghai Aladdin Co., Ltd. (China). Sulfuric acid $\left(\mathrm{H}_{2} \mathrm{SO}_{4}\right)$ and hydrochloric acid $(\mathrm{HCl})$ were bought from Beijing Chemical Co., Ltd. (China). Ammonium sulfate [ $\left.\left(\mathrm{NH}_{4}\right)_{2} \mathrm{SO}_{4}\right]$, sodium hydroxide $(\mathrm{NaOH})$, phenolphthalein, hexamethylene tetramine, cresol red, zinc powder and xylenol orange were all purchased from Tianjin Kermel Chemical Reagent Co., Ltd. (China). Ethylene diamine tetraacetic acid disodium salt (EDTA) was supplied by Beijing Yili Chemical Reagent Co., Ltd.

\section{Instruments}

SEM (JSM-7500F, JEOL, Japan) was employed to analyze the surface morphology and composition of the synthesized samples. TEM (JEM2100, JEOL, Japan) was used for observing the ultrastructure changes of the samples. FTIR (IS10, Thermo Fisher Scientific, USA) was used to analyze the chemical composition in the specimens of $\beta-\mathrm{CD}, \mathrm{TiO}_{2}$ and $\beta-\mathrm{CD} / \mathrm{TiO}_{2}$. Photocatalytic degradation of $\mathrm{MO}$ by $\beta-\mathrm{CD} / \mathrm{TiO}_{2}$ was carried out under ultraviolet light using a $250-\mathrm{W}$ high pressure mercury lamp and supplied by Jiguang special lighting electrical appliance factory (Shanghai, China). The progress of photocatalytic degradation was monitored by observing the disappearance of the absorption peak of MO at $463 \mathrm{~nm}$ by an ultraviolet and visible spectrophotometer (TU-1901, Beijing, China).

* E-mail: thundersking@aliyun.com Received June 8, 2017; accepted August 10, 2017. 


\section{Synthesis of a $\beta$-CD/TiO 2 composite}

The photoinduced assembly method ${ }^{[25,26]}$ was used for synthesis of a $\beta-\mathrm{CD} / \mathrm{TiO}_{2}$ composite in this procedure. In details, a $\beta-\mathrm{CD} / \mathrm{TiO} \mathrm{O}_{2}$ composite was synthesized by the addition of $\mathrm{TiO}_{2}(2.0 \mathrm{~g})$ and $\beta$-CD $(1.8 \mathrm{~g})$ into $100 \mathrm{~mL}$ of distilled water, then irradiated by a $250-\mathrm{W}$ high pressure mercury lamp for $30 \mathrm{~min}$. The precipitation was centrifuged and washed with $100 \mathrm{~mL}$ of distilled water for 2-3 times until the $\beta$-CD could not be detected by phenolphthalein probe technology. ${ }^{[27,28]}$ Then the product was dried in a vacuum oven at $50{ }^{\circ} \mathrm{C}$ for $12 \mathrm{~h}$ and the weight of product was recorded. The product was ground and well homogenized in the ball mill (100 mesh) before using.

\section{Determination of the active $\beta$-CD by means of phenolphthalein probe technology}

For evaluating the encapsulation ability of $\beta$-CD on $\mathrm{TiO}_{2}$, Mäkelä et al. ${ }^{[27]}$ put forward a method to measure $\beta$-cyclodextrin concentration based on the decolorization of phenolphtalein after embedding into the cavity of cyclodextrins. Also, our previous work of phenolphthalein probe technology was applied here. ${ }^{[28,29]}$ The absorbance of the calibration solutions of CDs was measured at the wavelength of $553 \mathrm{~nm}$ at room temperature. The contents of $\beta-\mathrm{CD}\left(c_{\mathrm{CD}}\right)$ could be calculated by Eq. (1), where $\Delta A$ denotes the difference between the $\mathrm{UV}$ absorbance of diluted separation filtrates and that of $\beta$-CD blank (phenolphthalein solutions without addition of $\beta$-CD).

$$
\Delta A=1.565 c_{C D}+0.011
$$

The contents of active $\beta$-CD in a $\beta$ - $\mathrm{CD} / \mathrm{TiO}_{2}$ composite were evaluated by Eq. (2), where $c$ represents the active $\beta$-CD concentration of $\beta-\mathrm{CD} / \mathrm{TiO}_{2}$ composite $\left(\mathrm{mol} \mathrm{L}^{-1}\right), c_{0}$ represents the $\beta$-CD concentration of $\beta$-CD blank sample (impregnated solution without addition of $\beta$-CD) (mol L $\mathrm{L}^{-1}$ ), M represents the $\beta$-CD molecular weight of $1135 \mathrm{~g} \mathrm{~mol}^{-1}, m$ denotes the weight of dry $\beta$-CD/TiO 2 composite (g).

$$
\text { Active } \beta-\mathrm{CD} \text { content }(\%)=\frac{\left(c-c_{0}\right) \times 0.1 \times \mathrm{M}}{m} \times 100 \%
$$

\section{Determination of $\mathrm{TiO}_{2}$ by means of back titration method}

In order to determine completely the contents of $\mathrm{TiO}_{2}$ in $\beta$-CD/ $\mathrm{TiO}_{2}$ composite, a self-designed back titration method was used. Three steps of dissolution-conversion-back titration were applied here.

Firstly, $0.1 \mathrm{~g}$ of composite was placed in an oven until completely carbonized and then transferred to a muffle furnace and heated at $800{ }^{\circ} \mathrm{C}$ for $2 \mathrm{~h}$ to afford the white powder. After the heat treatment, the samples were cooled by quenching in air to room temperature and then $5 \mathrm{~g}$ of $\left(\mathrm{NH}_{4}\right)_{2} \mathrm{SO}_{4}$ and $10 \mathrm{~mL}$ of $98 \%$ (wt\%) $\mathrm{H}_{2} \mathrm{SO}_{4}$ were added. The mixture was dissolved in $100 \mathrm{~mL}$ of distilled water after digestion.

Then, $10 \mathrm{~mL}$ of aqueous solution obtained from above was accurately moved into a $250 \mathrm{~mL}$ conical flask. $20 \mathrm{~mL}$ of $0.01 \mathrm{~mol} \mathrm{~L}^{-1}$ EDTA standard solution and 2 drops of cresol red indicator were added. The $\mathrm{pH}$ of the solution was adjusted by adding $0.1 \mathrm{~mol} \mathrm{~L}^{-1}$ $\mathrm{NaOH}$ solution drop by drop until the color change from red to yellow. The solution was boiled for $2 \mathrm{~min}$ and then cooled to room temperature. After adding 2-4 drops of xylenol orange, 1:1 $(V / V)$ $\mathrm{NH}_{3} \cdot \mathrm{H}_{2} \mathrm{O}$ was used to adjust the solution from yellow to reddish. 10 $\mathrm{mL}$ of hexamethylene tetramine buffer was added, and the solution changed bright yellow.

Excess EDTA was titrated by $0.01 \mathrm{~mol} \mathrm{~L}^{-1}$ standard solution of zinc, using the sharp color change of indicator, from bright yellow to shallow brown red, shaken well and allowed to stand for 1-2 min to determine the endpoint. The amounts of $\mathrm{TiO}_{2}(m)$ were calculated by Eq. (3), where $\mathrm{M}$ represents the $\mathrm{TiO}_{2}$ molecular weight of $79.87 \mathrm{~g}$ $\mathrm{mol}^{-1}, c$ is the concentration of zinc standard solution $\left(0.01 \mathrm{~mol} \mathrm{~L}^{-1}\right)$,
$V$ denotes the back titration amounts of zinc standard solution $(\mathrm{mL})$.

$$
m=\mathrm{M} \times(0.0002-c V)
$$

\section{Photocatalytic experiment}

Figure 1 showed the scheme of the self-designed photocatalytic reactor. In order to study the effect of $\beta-\mathrm{CD} / \mathrm{TiO}_{2}$ composite on photocatalytic degradation of $\mathrm{MO}$, pure $\mathrm{TiO}_{2}$ was used for comparison. Keeping the contents of $\mathrm{TiO}_{2}$ constant, the photocatalytic materials of pure $\mathrm{TiO}_{2}$ and $\beta-\mathrm{CD} / \mathrm{TiO}_{2}$ were tested, respectively.

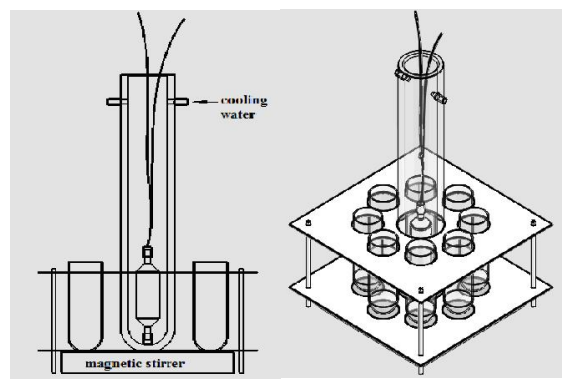

Figure 1 Schematic diagram of photocatalytic reactor.

$\mathrm{TiO}_{2}(0.0971 \mathrm{~g})$ and $\beta-\mathrm{CD} / \mathrm{TiO}_{2}(0.1 \mathrm{~g})$ were mixed with $100 \mathrm{~mL}$ of $0.1 \mathrm{mmol} \mathrm{L}^{-1} \mathrm{MO}$ solution in a $150 \mathrm{~mL}$ quartz test tube, respectively. Prior to irradiation, the reaction mixture remained in dark and stirred for $30 \mathrm{~min}$ to obtain adsorption equilibrium. Then the quartz test tubes were immediately irradiated with a $250-\mathrm{W}$ high-pressure mercury lamp in our self-designed photocatalytic reactor (Figure 1). During the experiment, quartz test tubes were taken out of the reactor one by one at different time intervals. Before analysis, each sample in the tube was centrifuged. The reaction progress was monitored at $463 \mathrm{~nm}$. Every solution was tested for three times.

In the UV-vis absorption spectra, the absorbance $(A)$ and concentration $\left(c, \mathrm{~mol} \mathrm{~L}^{-1}\right)$ were in accordance with Lambert-Beer law as shown in Eq. (4), where $\varepsilon$ represents the molar absorption coefficient $\left(\mathrm{L} \mathrm{mol}^{-1} \mathrm{~cm}^{-1}\right)$ and $\mathrm{b}$ denotes the optical path length $(\mathrm{cm})$.

$$
A=\varepsilon \mathrm{b} c
$$

The photocatalytic degradation efficiency $R^{[29-31]}$ was evaluated by Eq. (5), where $c_{0}$ and $c$ represent the concentration $\left(\mathrm{mol} \mathrm{L}^{-1}\right)$ of MO before and after photocatalytic degradation, $A_{0}$ and $A$ denote the absorbance of $\mathrm{MO}$ before and after photocatalytic degradation.

$$
R=\left(c_{0}-c\right) / c_{0} \times 100 \%=\left(A_{0}-A\right) / A_{0} \times 100 \%
$$

\section{The function of initial solution $\mathrm{pH}$}

In order to study the effect of initial solution $\mathrm{pH}$ on the degradation efficiency of $\mathrm{MO}$ by $\beta-\mathrm{CD} / \mathrm{TiO}_{2}$, the degradation efficiency under the $\mathrm{pH}=2,4,6,8$ and 10 were measured. In brief, 5 equiponderous $\beta-\mathrm{CD} / \mathrm{TiO}_{2}$ samples were mixed with isoconcentration solutions of $\mathrm{MO}\left(0.1 \mathrm{mmol} \mathrm{L}^{-1}\right)$ in our self-designed photocatalytic reactor, respectively. The $\mathrm{pH}$ was adjusted by $\mathrm{HCl}$ and $\mathrm{NaOH}$, respectively. After 30 min of dark adsorption, the quartz test tubes were immediately irradiated with a $250-\mathrm{W}$ high-pressure mercury lamp for 20 min under the same experiment conditions. Then the progress of photocatalytic degradation under different initial $\mathrm{pH}$ was monitored by observing the disappearance of the absorption peak of MO at 463 $\mathrm{nm}$.

\section{Recycle experiments}

The regeneration performance of $\beta-\mathrm{CD} / \mathrm{TiO}_{2}$ was tested by carrying out 5 cycles of photocatalytic degradation experiments. The $\beta-\mathrm{CD} / \mathrm{TiO}_{2}$ was collected after the first photocatalytic degradation 
experiment. After washing, drying and grinding, the composite was added into photocatalytic system and the procedures presented in "Photocatalytic experiment" were implemented.

\section{Results and Discussion}

\section{Surface morphology study}

SEM analysis of the $\beta-\mathrm{CD} / \mathrm{TiO}_{2}$ composite using $\beta-\mathrm{CD}$ and $\mathrm{TiO}_{2}$ as references was investigated in this study and the images were listed in Figure 2. $\beta$-CD was seen to have a lamellar structure that existed in an amorphous form (Figure 2a). On the other hand, the unmodified $\mathrm{TiO}_{2}$ demonstrated a nanoscale spherical shape and agglomerated together (Figure 2b). The surface of $\beta-\mathrm{CD} / \mathrm{TiO}_{2}$ (Figure 2c) could be observed with lots of irregularly shaped crystals, which showed no obvious difference on the morphology and particle size with pure $\mathrm{TiO}_{2}$. Thus, the presence of $\beta-\mathrm{CD}$ in $\beta-\mathrm{CD} / \mathrm{TiO}_{2}$ could not be confirmed by SEM.
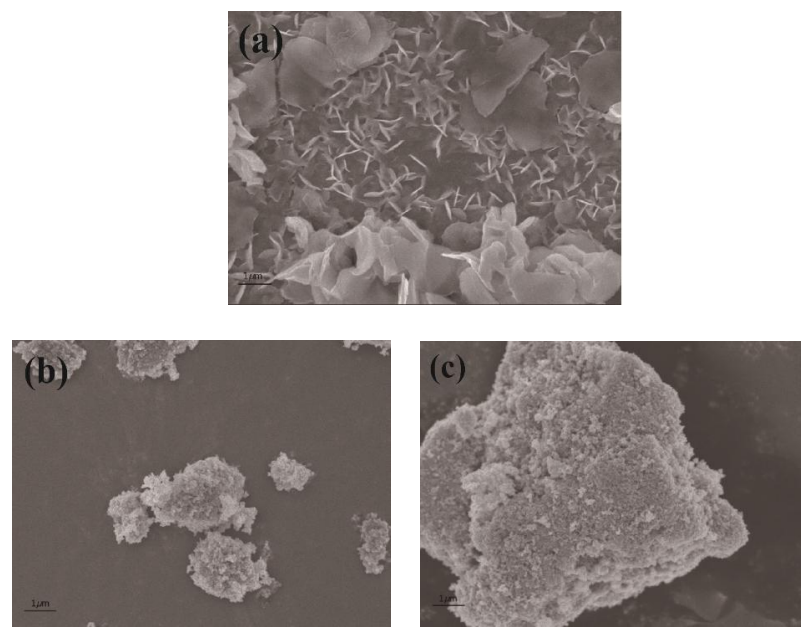

Figure 2 SEM images of (a) $\beta$-CD $(\times 10000)$; (b) $\mathrm{TiO}_{2}(\times 10000)$; (c) $\beta-\mathrm{CD} / \mathrm{TiO}_{2}(\times 10000)$.

The FTIR spectra of $\beta-\mathrm{CD}, \mathrm{TiO}_{2}$ and $\beta-\mathrm{CD} / \mathrm{TiO}_{2}$ were shown in Figures $3 \mathrm{a}, 3 \mathrm{~b}$ and $3 \mathrm{c}$, respectively. By comparing the spectra, the existence of $\beta$-CD in the composite of $\beta-\mathrm{CD} / \mathrm{TiO}_{2}$ can be proved. In Figures $3 \mathrm{a}$ and $3 \mathrm{c}$, there were three weak bands at 1154, 1078 and $1030 \mathrm{~cm}^{-1}$, which were attributed to the stretching vibrations of $\mathrm{C}-\mathrm{O}$ bond of $\mathrm{CD}$. However, they cannot be observed in the Figure $3 \mathrm{~b}$.

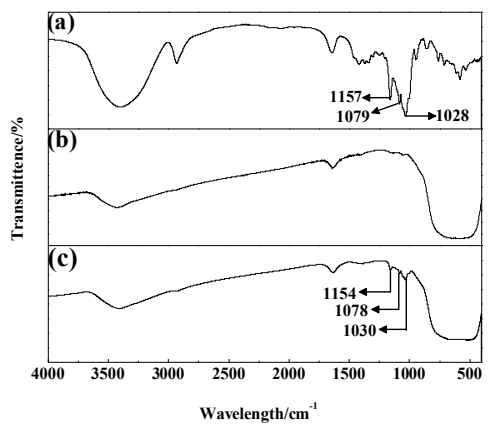

Figure 3 FTIR spectrum of (a) $\beta$-CD; (b) $\mathrm{TiO}_{2}$; (c) $\beta$-CD/TiO composite.

TEM analysis was applied for further examination. The particles of $\mathrm{TiO}_{2}$ (Figure 4a) and $\beta$ - $\mathrm{CD} / \mathrm{TiO}_{2}$ (Figure $4 \mathrm{~b}$ ) were all agglomerated together and both of the particle diameters were below 100 nanometers with spherical morphology. In Figure $4 \mathrm{~b}$, the dark-field imaging area of the particles increased significantly than that in Fig- ure $4 \mathrm{a}$, indicating that the aggregation effect of $\beta-\mathrm{CD} / \mathrm{TiO}_{2}$ was more obvious. It was also demonstrated that $\beta$-CD was loaded onto the surface of nano- $\mathrm{TiO}_{2}$ instead of embedded in $\mathrm{TiO}_{2}$.
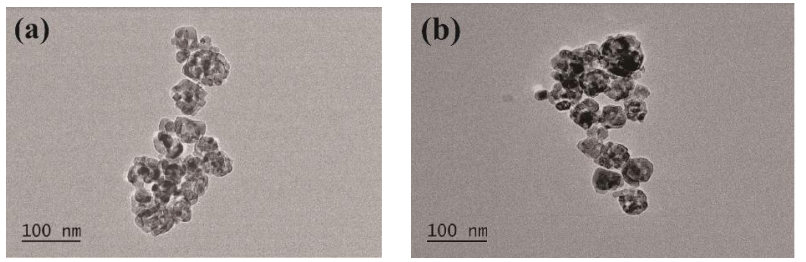

Figure 4 (a) TEM images of $\mathrm{TiO}_{2}$; (b) TEM images of $\beta$-CD/TiO 2 .

\section{The components of active $\beta-\mathrm{CD}$ and $\mathrm{TiO}_{2}$ in $\beta-\mathrm{CD} / \mathrm{TiO}_{2}$ compo-} site

Due to the phenomenon of purple phenolphthalein solution became colorless in the presence of $\beta$-CD, the surface active $\beta$-CD contents on $\beta-\mathrm{CD} / \mathrm{TiO}_{2}$ had been determined by our previous research work. ${ }^{[28,32]}$ The purple phenolphthalein solution $(\mathrm{pH}=10.5)$ faded by mixing the $\beta-\mathrm{CD} / \mathrm{TiO}_{2}$ powder in dark. The solution was kept overnight to balance. The active $\beta$-CD contents on the surface of $\beta$-CD/ $\mathrm{TiO}_{2}$ were determined as $2.0 \%$ (wt $\%$ ), which not only demonstrated a successful grafting of $\beta$-CD macromolecules but also verified the encapsulating ability of $\beta-\mathrm{CD} / \mathrm{TiO}_{2}$ composite.

The contents of $\mathrm{TiO}_{2}$ in $\beta$-CD/TiO 2 composite were detected by means of back titration method. Gravimetric method was not applicable, because the co-existence of rutile and anatase phase led to the uncertainty of residue's composition after the process of ashing $\left(800{ }^{\circ} \mathrm{C}, 2 \mathrm{~h}\right)$. By means of back titration method, the contents of $\mathrm{TiO}_{2}$ in $\beta-\mathrm{CD} / \mathrm{TiO}_{2}$ composite were detected as $0.0971 \pm 0.0006 \mathrm{~g} / 0.1$ $\mathrm{g}$ (5 times of determination).

\section{Photocatalytic performance analysis}

The photocatalytic effects of $\mathrm{TiO}_{2}$ and $\beta-\mathrm{CD} / \mathrm{TiO}_{2}$ on the degradation of MO under the $250-\mathrm{W}$ high-pressure mercury lamp were studied, and the results are shown in Figure 5. Figure 5 was divided into two phases, one was dark-adsorbing for $30 \mathrm{~min}$ and the subsequent was photocatalytic degradation. The role of $\mathrm{CD}$ is multifunctional. In dark-adsorbing phase, $\beta$-CD plays a major role in adsorption as seen from the reduction of MO concentration in the solution in the presence of $\beta-\mathrm{CD} / \mathrm{TiO}_{2}$. During the photocatalytic degradation phase, both undegraded $\mathrm{MO}$ and the intermediate of $\mathrm{N}, \mathrm{N}$-dimethylaniline can be included by $\beta$-CD providing close proximity of MO to the catalyst. Furthermore, $\beta$-CD plays electron-donating and holecapturing roles. ${ }^{[23]}$

Before photocatalytic reaction, the two materials were kept in $\mathrm{MO}$ solutions with isoconcentration and stirred in dark for $30 \mathrm{~min}$ to reach adsorption equilibrium, respectively. After dark adsorption, the $c / c_{0}$ values of $\mathrm{MO}$ by $\mathrm{TiO}_{2}$ and $\beta-\mathrm{CD} / \mathrm{TiO}_{2}$ were 0.9960 and 0.8456 , respectively. The interaction between $\mathrm{TiO}_{2}$ and $\mathrm{MO}$ led to a little adsorption of MO $\left(0.0040,1-c / c_{0}\right)$, which was much lower than that of $\beta-\mathrm{CD} / \mathrm{TiO}_{2}(0.1544)$. It meant that $\beta-\mathrm{CD} / \mathrm{TiO}_{2}$ exhibited an improved adsorption ability comparing to $\mathrm{TiO}_{2}$, which demonstrated a relative strong binding affinity between $\beta$-CD and $\mathrm{MO}$. This strong binding affinity had been proved by the work of Kompany-Zareh et $a l .{ }^{[33]}$

After dark adsorption, MO was degraded and the possible pathways were likely to be as follows. ${ }^{[34]}$

$$
\begin{aligned}
& \mathrm{TiO}_{2}+h v \rightarrow \mathrm{h}^{+}+\mathrm{e}^{-} \\
& \mathrm{e}^{-}+\mathrm{O}_{2} \rightarrow \mathrm{O}_{2}{ }^{--} \\
& \mathrm{h}^{+}+\mathrm{H}_{2} \mathrm{O} \rightarrow \cdot \bullet \mathrm{OH}+\mathrm{H}^{+} \\
& \mathrm{O}_{2}{ }^{-}+\mathrm{MO} \rightarrow \text { degraded products } \\
& \cdot \mathrm{OH}+\mathrm{MO} \rightarrow \text { degraded products }
\end{aligned}
$$


The photocatalytic degradation of $\mathrm{MO}$ was mainly caused by the superoxide anion free radicals $\left(\mathrm{O}_{2}{ }^{--}\right)$and the hydroxyl radicals $(\bullet \mathrm{OH})$, which were photoinduced by $\mathrm{TiO}_{2}$ under a $250-\mathrm{W}$ high-pressure mercury lamp. ${ }^{[35-37]}$

The degradation rates of $\mathrm{MO}$ by $\mathrm{TiO}_{2}$ and $\beta-\mathrm{CD} / \mathrm{TiO}_{2}$ were calculated by Eq. (6), where $c_{0}$ and $c$ represent the concentration of MO before and after photocatalytic degradation $\left(\mathrm{mol} \mathrm{L}^{-1}\right), t$ represents the photocatalytic degradation time of MO.

$$
\text { Degradation rate }=\frac{d\left(c / c_{0}\right)}{d t}
$$

In Figure 5, the degradation rate of $\mathrm{MO}$ by $\beta-\mathrm{CD} / \mathrm{TiO}_{2}$ was higher than by $\mathrm{TiO}_{2}$, and the degradation time was shortened by the introduction of $\beta$-CD. The role of $\beta-\mathrm{CD}$ in photocatalytic reaction system is illustrated in Figure 6 . The enhancement of degradation of MO was probably due to azo type of MO entering into the cavity of $\beta$-CD. The benzenesulfonate side uncovered interacted with $\mathrm{TiO}_{2}$ more easily by electrostatic forces than without $\beta$-CD under the effect of electron-holes $\left(\mathrm{h}^{+}\right) .{ }^{[38]}$ Furthermore, according to the literature, ${ }^{[3,40]}$ the azo type of $\mathrm{MO}$ can be finally decomposed into $\mathrm{CO}_{2}$ and $\mathrm{H}_{2} \mathrm{O}$ in the presence of the hydroxyl radicals $(\cdot \mathrm{OH})$, as seen in Figure 7 . The physical map that $\mathrm{MO}$ was degraded by $\mathrm{TiO}_{2}$ and $\beta-\mathrm{CD} / \mathrm{TiO}_{2}$ at different time intervals was shown in Figure 8.

Based on the above results, we can draw the preliminary conclusion that the enhancement of photocatalytic degradation of MO could be dependent on the introduction of $\beta$-CD in two aspects. On the one hand, $\mathrm{MO}$ in this photocatalytic degradation system is included by the hydrophobic cavity of $\beta$-CD and the concentration of MO rised on the surface of $\mathrm{TiO}_{2}$. On the other hand, $\beta$-CD plays electron-donating and hole-capturing roles when linked to $\mathrm{TiO}_{2}$, which makes further improvement of photocatalytic degradation efficiency. ${ }^{[41]}$

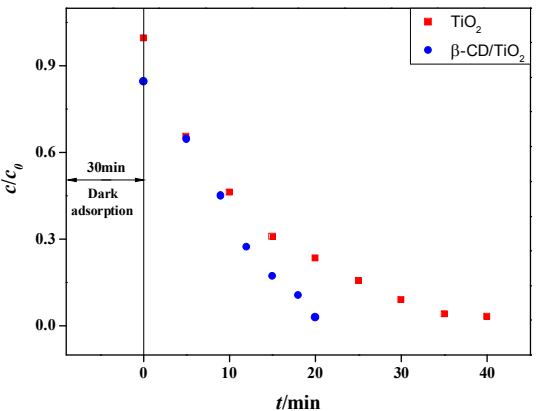

Figure 5 Photocatalytic degradation curves of methyl orange by $\mathrm{TiO}_{2}$ and $\beta-\mathrm{CD} / \mathrm{TiO}_{2}(\mathrm{pH}=3.7)$.

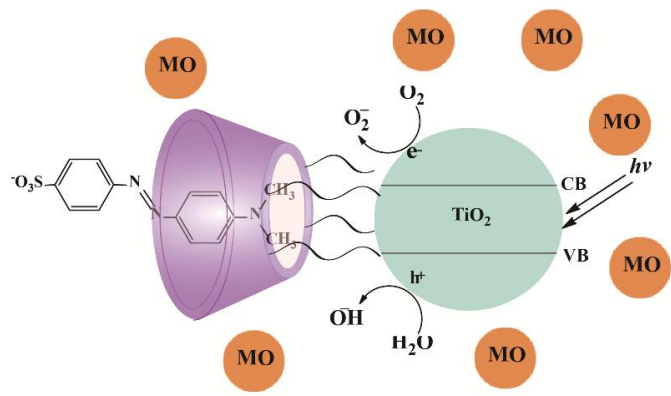

Figure 6 The role of $\beta$-CD in $\mathrm{TiO}_{2}$ photocatalytic reaction system.

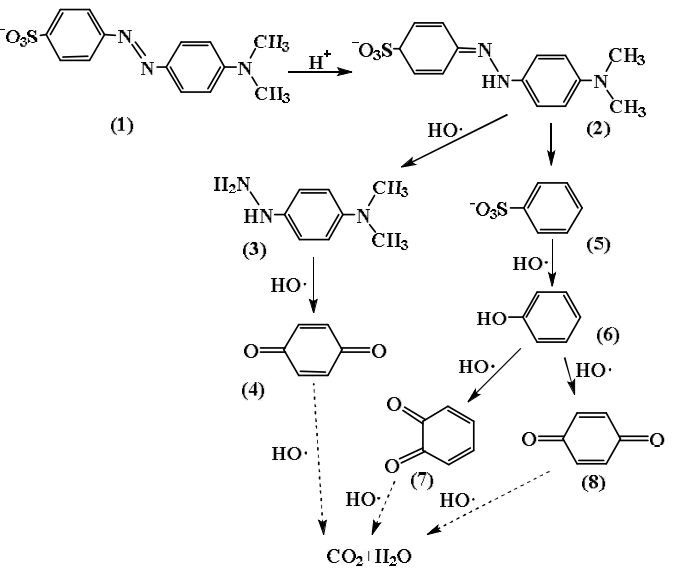

Figure 7 Decomposition mechanism of methyl orange. ${ }^{[39]}$
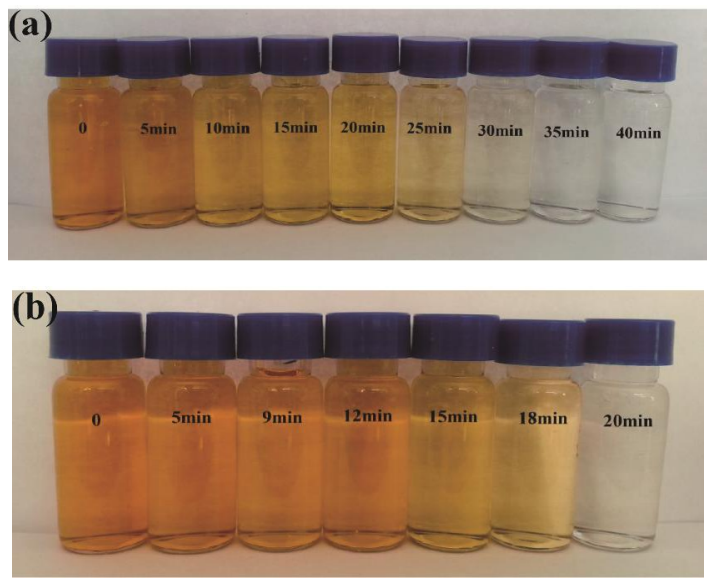

Figure 8 Physical map of MO photocatalytic degraded by $\mathrm{TiO}_{2}$ (a) and $\beta-\mathrm{CD} / \mathrm{TiO}_{2}(\mathrm{~b})$ at different time intervals.

\section{Kinetic study}

Three kinetic models can be applied to investigate the mechanism of the degradation process as shown in Figure 9. According to literature, the pseudo-zero order kinetic model is based on the assumption that the photocatalytic degradation rate is only controlled by the irradiation time. ${ }^{[42,43]}$ While the pseudo-first order kinetic model and pseudo-second order kinetic model highlight that the rate-limiting step may be chemical sorption or chemisorption involving valence forces through sharing or exchange of electrons between sorbent and sorbate. ${ }^{[4,45]}$

The rate equations of the three different models were listed from Eq. (7) to Eq. (9), where $c_{0}$ is the initial concentration $\left(\mathrm{mmol} \mathrm{L}^{-1}\right)$ of $\mathrm{MO}$ and $c$ represents its concentration $\left(\mathrm{mmol} \mathrm{L}^{-1}\right)$ at time $t(\mathrm{~min}), k_{0}$ $\left(\mathrm{mmol} \mathrm{L}^{-1} \mathrm{~min}^{-1}\right), k_{1}\left(\mathrm{~min}^{-1}\right)$ and $k_{2}\left(\mathrm{~L} \mathrm{mmol}^{-1} \mathrm{~min}^{-1}\right)$ are the rate constants of pseudo-zero order kinetic model, pseudo-first order kinetic model and pseudo-second order kinetic model, respectively.

The pseudo-zero order equation:

$$
c=c_{0}-k_{0} t
$$

The pseudo-first order equation:

$$
\ln c=-k_{1} t+\ln c_{0}
$$

The pseudo-second order equation:

$$
t / c=\frac{1}{\left(k_{2} c_{0}^{2}\right)}+t / c_{0}
$$



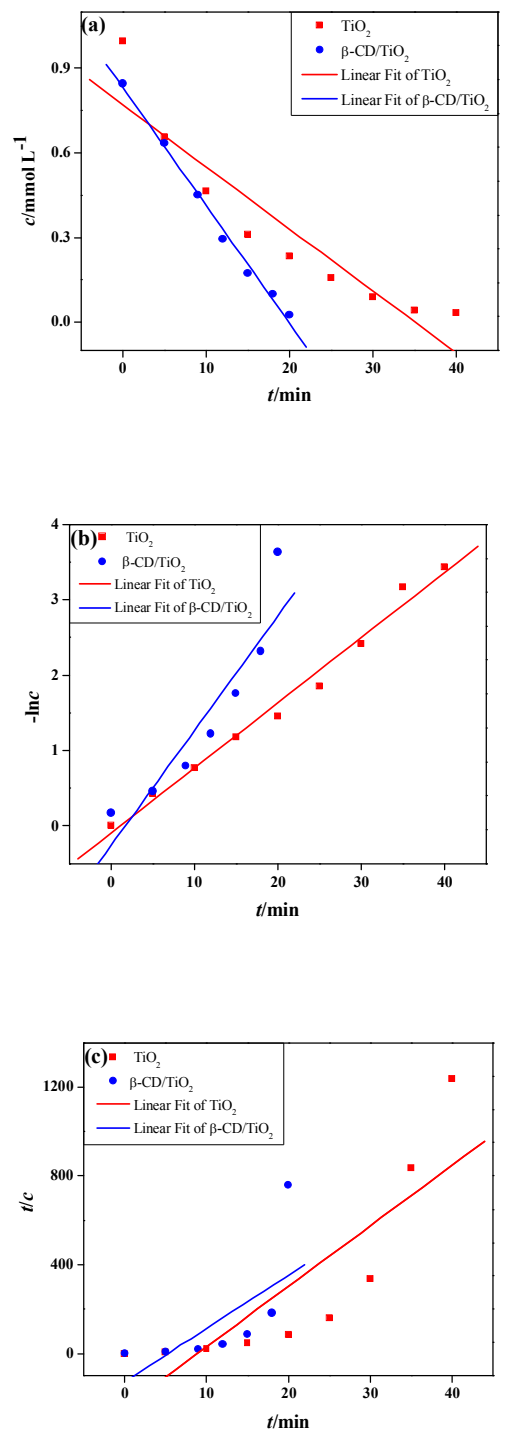

Figure 9 kinetic model for the photocatalytic degradation of MO by pure $\mathrm{TiO}_{2}$ and $\beta-\mathrm{CD} / \mathrm{TiO}_{2}$ : (a) plots of pseudo-zero order kinetic mode; (b) pseudo-first order kinetic model; (c) pseudo-second order kinetic model.

The kinetic parameters for the different rate equations were determined by linear and nonlinear curve fittings and the results were listed in Table 1. It was found that the photocatalytic degradation of $\mathrm{MO}$ by $\mathrm{TiO}_{2}$ fitted to pseudo-first order kinetic model, however, the photocatalytic degradation by $\beta-\mathrm{CD} / \mathrm{TiO}_{2}$ fitted to pseudo-zero order kinetic model. Pseudo-zero order kinetic model gave better correlations for the photocatalytic degradation of $\mathrm{MO}$ by $\beta-\mathrm{CD} / \mathrm{TiO}_{2}$. Hence, the photocatalytic degradation rate is only controlled by the irradiation time.

The possible reasons affecting the fitting result of kinetic model were as follows: for the inclusion associations between $\beta$-CD and $\mathrm{MO}$, after the dark adsorption, $\mathrm{MO}$ [part (3) in Figure 7] entered into the cavity of $\beta$-CD firstly, ${ }^{[46]}$ and then MO [part (5) in Figure 7] was concentrated on the surface of $\mathrm{TiO}_{2}$ gradually so as to the photocatalytic process happened. This resulted in the degradation rate mainly controlled by time $t$ finally.

\section{The function of $\mathrm{pH}$ on the photocatalytic degradation efficiency}

The degradation efficiency of MO by $\beta-\mathrm{CD} / \mathrm{TiO}_{2}$ under the dif-
Table 1 Parameters of three kinetic models

\begin{tabular}{cccc}
\hline $\begin{array}{c}\text { Kinetic } \\
\text { model }\end{array}$ & & $\mathrm{TiO}_{2}$ & $\beta-\mathrm{CD} / \mathrm{TiO}_{2}$ \\
\hline $\begin{array}{c}\text { Pseudo-zero } \\
\text { order }\end{array}$ & $R^{2}$ & 0.8671 & 0.9926 \\
& Fitted curve & $c=-0.022 t+0.7707$ & $c=-0.0417 t+0.8306$ \\
$\begin{array}{c}\text { Pseudo-first } \\
\text { order }\end{array}$ & Fitted curve & $-\ln c=0.0864 t-0.0965$ & $-\ln c=0.1563 t-0.2848$ \\
$\begin{array}{c}\text { Pseu- } \\
\text { do-second } \\
\text { order }\end{array}$ & Fitted curve & $t / c=27.234 t-241.3$ & $t / c=26.297 t-140.24$ \\
\hline & $R^{2}$ & 0.7189 & 0.4773 \\
\hline
\end{tabular}

ferent initial $\mathrm{pH}$ was shown in Figure 10. As shown in Figure 10, the photocatalytic degradation efficiency increased with decrease of the solution $\mathrm{pH}$. The reason for the improvement of the degradation efficiency was attributed to the increase of the the positive charge on the surface of $\mathrm{TiO}_{2}$ particles due to acidic environment, furthermore, $\beta$-CD could restrain the recombination of photogenerated electron-hole pairs. ${ }^{[4]}$ Therefore, the anionic dye of MO was easily accumulated on the surface of the $\mathrm{TiO}_{2}$ particles. After dark-adsorbing for $30 \mathrm{~min}$, the initial concentration of MO was raised, and this phenomenon can result in an enhancement of photocatalytic degradation efficiency.

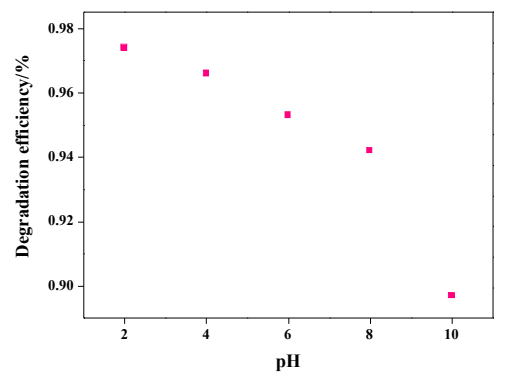

Figure 10 The degradation rate of $\mathrm{MO}$ by $\beta-\mathrm{CD} / \mathrm{TiO}_{2}$ under the different initial $\mathrm{pH}$.

\section{Recycle performance}

The regeneration performance of $\beta-\mathrm{CD} / \mathrm{TiO}_{2}$ was tested by 5 cycles of photocatalytic degradation experiments. The result of degradation efficiency in recycle experiment was shown in Figure 11. It could be seen that $\beta-\mathrm{CD} / \mathrm{TiO}_{2}$ still kept high degradation efficiency after 5 cycles. Photocatalytic degradation curves of recycle experiments by $\beta-\mathrm{CD} / \mathrm{TiO}_{2}$ were shown in Figure 12 . The degradation efficiency of MO changed slightly, and the degradation rate basically remained unchanged. The pseudo-zero order kinetic model of recycle experiment was shown in Table 2. According to the fitted equation in this table, the sorption capacity is slightly decreased with the number of recycling. Therefore, $\beta-\mathrm{CD} / \mathrm{TiO}_{2}$ composite retained stable during the process, indicating a good regeneration property and a high photocatalytic activity.

\section{Conclusions}

The $\beta$ - $\mathrm{CD} / \mathrm{TiO}_{2}$ composite was synthesized by photoinduced assembly method and $\beta$-CD was loaded onto the surface of nano- $\mathrm{TiO}_{2}$. The contents of active $\beta-\mathrm{CD}$ and $\mathrm{TiO}_{2}$ in $\beta-\mathrm{CD} / \mathrm{TiO}_{2}$ were determined as $2.0 \%$ and $0.0971 \pm 0.0006 \mathrm{~g} / 0.1 \mathrm{~g}$, respectively. $100 \mathrm{~mL}$ of 0.1 mmol L ${ }^{-1} \mathrm{MO}$ could be completely degraded photocatalytically in 20 


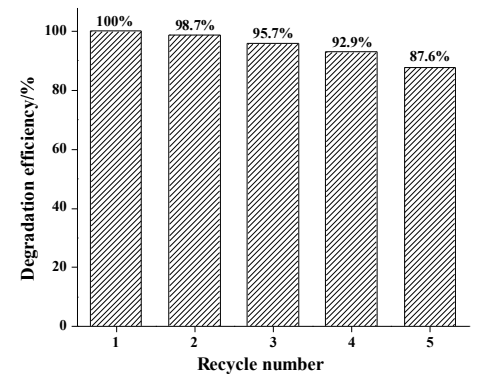

Figure 11 The regeneration performance of $\beta-\mathrm{CD} / \mathrm{TiO}_{2}$.

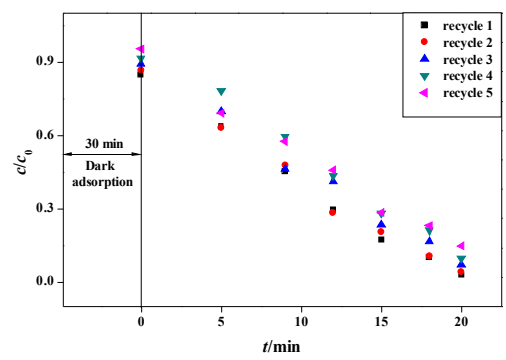

Figure 12 Photocatalytic degradation curves of recycle experiments by $\beta-\mathrm{CD} / \mathrm{TiO}_{2}$.

Table 2 Pseudo-zero order kinetic model of recycle experiment

\begin{tabular}{ccc}
\hline Recycle times & Fitted curve & $R^{2}$ \\
\hline Recycle 1 & $c=-0.0417 t+0.8306$ & 0.9926 \\
Recycle 2 & $c=-0.0416 t+0.8416$ & 0.9900 \\
Recycle 3 & $c=-0.0411 t+0.8827$ & 0.9901 \\
Recycle 4 & $c=-0.0422 t+0.9478$ & 0.9899 \\
Recycle 5 & $c=-0.0397 t+0.9239$ & 0.9898 \\
\hline
\end{tabular}

min by $\beta-\mathrm{CD} / \mathrm{TiO}_{2}$, the degradation time was $43 \%$ shorter than that by pure $\mathrm{TiO}_{2}$. Thus, $\beta-\mathrm{CD} / \mathrm{TiO}_{2}$ demonstrates an excellent degradation performance. The kinetics of photocatalytic degradation of $\mathrm{MO}$ by $\beta-\mathrm{CD} / \mathrm{TiO}_{2}$ fitted the model of pseudo-zero order during the process. In addition, the composite of $\beta-\mathrm{CD} / \mathrm{TiO}_{2}$ showed a good photocatalytic activity and regeneration property after 5 recycle experiments.

\section{Acknowledgement}

This study is supported by the National Natural Science Fund of China (No. 51403030) and the Fundamental Research Funds for the Central Universities of China (No. 2572017CB23).

\section{References}

[1] Yang, Q. S.; Liao, Y. J.; Mao, L. L. Chin. J. Chem. Eng. 2012, 20, 572.

[2] Tang, Y. N.; Di, W. H.; Zhai, X. S.; Yang, R. Y.; Qin, W. P. ACS Catal. 2013, 3, 405 .

[3] Kordouli, E.; Bourikas, K.; Lycourghiotis, A.; Kordulis, C. Catal. Today 2014, 252, 128

[4] Kuriechen, S. K.; Murugesan, S. Water Air Soil Poll. 2013, 224, 1671.

[5] Zhao, F. H.; Dong, B. H.; Gao, R. J.; Su, G.; Liu, W.; Shi, L.; Xia, C. H. Appl. Surf. Sci. 2015, 351, 303

[6] Dadvar, E.; Kalantary, R. R.; Panahi, H. A.; Peyravi, M. J. Chem. 2017,
2017, 1.

[7] Man, X. L.; Wu, R. L.; Lv, H. H.; Wang, W. J. Appl. Polym. Sci. 2015 , $132,42627$.

[8] Yasin, A. S.; Obaid, M.; Newehy, M. H. E.; Deyab, S. S. A.; Barakat, N. A. M. Ceram. Int. 2015, 41, 11876.

[9] Tangale, N. P.; Belhekar, A. A.; Kale, K. B.; Awate, S. V. Water Air and Soil Poll. 2014, 225, 1847.

[10] Djellabi, R.; Ghorab, M. F. Desalin. Water Treat. 2015, 55, 1900.

[11] Ma, H. C.; An, R.; Chen, L. L.; Fu, Y. H.; Ma, C.; Dong, X. L.; Zhang, X. F. Electrochem. Commun. 2015, 57, 18.

[12] Liu, H.; Liu, T. T.; Dong, X. N.; Zhu, Z. F. Micro Nano Lett. 2015, 10, 435.

[13] Doan, D. H.; Kim, Y. J.; Nguyen, T. M.; Yoon, H. O. Water Air Soil Poll. 2015, 226, 2252.

[14] Zhang, X.; Wu, F.; Deng, N. S. J. Hazard. Mater. 2011, 185, 117.

[15] Szetjli, J. Chem. Rev. 1998, 98, 1743.

[16] Valle, E. M. M. D. Process Biochem. 2004, 39, 1033.

[17] Varan, G.; Varan, C.; Erdogar, N.; Hincal, A. A.; Bilensoy, E. Int. J. Pharm. 2017.

[18] Uitdehaag, J. C.; Ba, V. D. V.; Dijkhuizen, L. Proteins 2001, 43, 327.

[19] Shen, J.; Pang, J.; Kalwarczyk, T. J. Mater. Chem. C 2015, 3, 8104.

[20] Anandan, S.; Yoon, M. Catal. Commun. 2004, 5, 271.

[21] Anandan, S.; Yoon, M. Spectrochim. Acta A 2004, 60, 885.

[22] Pitchaimuthu, S.; Rajalakshmi, S.; Kannan, N. Desalin. Water. Treat. 2014, 52, 3392.

[23] Ali, M. M.; Sandhya, K. Y. Carbon 2014, 70, 249.

[24] Willner, I.; Eichen, Y.; Willner, B. Res. Chem. Intermed. 1994, $20,681$.

[25] Feng, J.; Miedaner, A.; Ahrenkiel, P.; Himmel, M. E.; Curtis, C.; Ginley, D. J. Am. Chem. Soc. 2005, 127, 14968.

[26] Zhou, W.; Pan, K.; Zhang, L. L.; Tian, C. G.; Fu, H. G. Phys. Chem. Chem. Phy. 2009, 11, 1713.

[27] Mäkelä, M.; Korpela, T.; Laakso, S. J. Biochem. Bioph. Meth. 1987, 14, 85.

[28] Wang, T.; Li, B.; Si, H. Y.; Lin, L. Surf. Interface Anal. 2011, 43, 1532.

[29] Zhang, X.; Wu, F.; Deng, N. S. Catal. Commun. 2010, 11, 422.

[30] Song, J.; Wang, X.; Chen, O. P.; Chen, C. K.; Chang, C. T. Sep. Sci. Technol. 2015, 50, 1394.

[31] Wang, G. H.; Wu, F.; Zhang, X.; Luo, M. D.; Deng, N. S. J. Photochem Photobiol. A 2006, 133, 85 .

[32] Si, H. Y.; Li, B.; Wang, T. Wood Sci. Technol. 2013, 47, 601.

[33] Kompany-Zareh, M.; Mokhtari, Z.; Abdollahi, H. Chemometr. Intell. Lab. 2012, 118, 230.

[34] Anas, M.; Han, D. S.; Mahmoud, K.; Park, H. Mat. Sci. Semicon. Proc. 2016, 41, 209.

[35] Zhang, X.; Li, X. K.; Deng, N. S. Ind. Eng. Chem. Res. 2011, 51, 704.

[36] Liu, S. H.; Wang, S. L.; Sun, X. Y.; Li, W. Z.; Ni, Y. M.; Wang, W. F.; Wang, M.; Yao, S. D. Acta Chim. Sinica 2004, 62, 818.

[37] Leong, K. H.; Liu, S. L.; Sim, L. C.; Saravanan, P.; Jang, M.; Ibrahim, S. Appl. Surf. Sci. 2015, 358, 370.

[38] Lu, P.; Liu, B.; Wu, F.; Deng, N. S. Chin. J. Appl. Chem. 2003, 20, 108.

[39] Han, J.; Zeng, H. Y.; Xu, S.; Chen, C. R.; Liu, X. J. Appl. Catal. A-Gen. 2016, 527,72 .

[40] Chu, J. Y.; Fan, D. J. Jiangsu Univ. 2010, 31, 469.

[41] Wang, G. H.; Wu, F.; Zhang, X.; Luo, M. D.; Deng, N. S. J. Hazard. Mater. 2006, 133, 85.

[42] Mhlanga, N.; Ray, S.S. J. Biol. Macromol. 2015, 72, 1301.

[43] Petrella, A.; Boghetich, G.; Petrella, M.; Mastrorilli, P.; Petruzzelli, V.; Petruzzelli, D. Ind. Eng. Chem. Res. 2014, 53, 2566.

[44] Zhang, M.; Helleur, R.; Zhang, Y. Carbohyd. Polym. 2015, 130, 206.

[45] Maruszewska, A.; Podsiadły, R. Color. Technol. 2014, 130, 243.

[46] Suzuki, M.; Sasaki, Y. J. Am. Chem. Soc. 1979, 27, 609

[47] Wu, Z.; Liu, H. Y.; Dai, D.; Liu, C. J. Sol-Gel. Sci. Technol. 2017, 83, 243. 